$\mathrm{mg} / 100 \mathrm{ml} ; \mathrm{IgM}, 120 \mathrm{mg} / 100 \mathrm{ml} ; \mathrm{IgA}, 170 \mathrm{mg} / 100 \mathrm{ml} ; \mathrm{IgE}, 52$ $\mathrm{mg} / 100 \mathrm{ml}$. Antinuclear antibody and latex fixation tests were negative but radioimmunoassay for DNA binding indicated $10.6 \%$ DNA binding, which was just above the upper limits of normal for that study. Progression of the skin lesions continued slowly with patchy depigmentation and increasing local fobrosis.

\section{REFERENCES AND NOTES}

1. Allansmith, M., McClellan, B. H., Butterworth, M., and Maloney, J. R.: The development of immunoglobulin levels in man. $J$. Pediat., 72: 276 (1968).

2. Burge, K. M., Perry, H. O., and Stickler, G. B.: "Familial" scleroderma. Arch. Dermatol., 99: 681 (1969).

3. Carr, R. I., Koffler, D., Agnello, V., and Kunkel, H. G.: Studies on DNA antibodies using DNA labelled with actinomycin-D $\left({ }^{3} \mathrm{H}\right)$ or dimethyl $\left({ }^{3} \mathrm{H}\right)$ sulfate. Clin. Exp. Immunol., 4: 527 (1969).

4. Currie, S., Saunders, M., and Knowles, M.: Immunologic aspects of systemic sclerosis: In vitro activity of lymphocytes from patients with the disorder. Brit. J. Dermatol., 84: 400 (1970).

5. Dixon, W. J., and Massey, F. J., Jr.: Introduction to Statistical Analysis, Ed. 2 (McGraw-Hill Book Company, Inc., Boston, 1957).

6. Fisher, E. R., and Rodnan, G. P.: Pathologic observations concerning the cutaneous lesion of progressive systemic sclerosis: An electron microscopic, histochemical and immunohistochemical study. Arthritis Rheum., 3: 536 (1960).

7. Fleischmajer, R., Damiano, V., and Nedwich, A.: Alteration of subcutaneous tissue in systemic scleroderma. Arch. Dermatol. 105: 59 (1972).

8. Fleischmajer, R., and Prunieras, M.: Generalized morphea. II. Electron microscopy of collagen, cells, and the subcutaneous tissue. Arch. Dermatol., 106: 515 (1972).

9. Friou, G.: Fluorescent spot test for antinuclear antibodies. Arthritis Rheum., 4: 407 (1962).

10. Hanson, V., Drexler, E., and Kornreich, H.: DNA antibodies in childhood scleroderma. Arthritis Rheum., 13: 798 (1970).

11. Hanson, V., Drexler, E., and Kornreich, H.: Rheumatoid factor (antigammaglobulins) in children with focal scleroderma. Submitted for publication.

12. Hayes, R. L., and Rodnan, G. P.: The ultrastructure of skin in progressive systemic sclerosis (scleroderma). I. Dermal collagen fibers. Amer. J. Pathol., 63: 433 (1971).

13. Hickman, J. W., and Sheils, W.: Progressive facial hemiatrophy. Arch. Intern. Med., 113: 716 (1964).

14. Holborow, E. J., and Johnson, G. D.: Immunoflourescence. In: D. M. Weir: Handbook of Experimental Immunology (Blackwell Scientific Publications, Oxford, 1967).

15. Kass, H., Hanson, V., and Patrick, J.: Scleroderma in childhood. J. Pediat. 68: 243 (1966).

16. Kass, H. K., Drexler, E., and Hanson, V.: Antinuclear factors in childhood rheumatic diseases. J. Pediat., 69: 1039 (1966).

17. Leroy, E. C.: Connective tissue systhesis by scleroderma skin fibroblasts in cell culture. J. Exp. Med., 135: 1351 (1972).

18. McGiven, A. R., deBoer, W. G. R. M., and Barnett, A. J.: Renal immune deposits in scleroderma. Pathology, 3: 145 (1971).

19. Oka, M, and Ruotsi, A.: Positive immuno-reactions in a case of unilateral scleroderma and progressive hemiatrophy. Acta Rheumatol. Scand., 15: 29 (1969).

20. Rodnan, G. P., and Medsger, T. A., Jr.: Musculoskeletal involvement in progressive systemic sclerosis (scleroderma). Bull. Rheum. Dis., 17: 419 (1966).

21. Schor, S.: Fundamentals of Biostatistics (G. P. Putnam's Sons, New York, 1968).

22. Seligman, M., Cannat, A., and Hamard, M.: Studies on antinuclear antibodies. Ann. N. Y. Acad. Sci., 124: 816 (1965).

23. Winkelman, R. K.: Classification and pathogenesis of scleroderma. Mayo Clin. Proc., 46: 83 (1971).

24. The present address of Lieutenant Commander G. A. MacPherson is: Rees-Stealy Medical Clinic, San Diego, Calif.

25. This paper was presented in part at the Society for Pediatric Research, May 1972, and XIII International Congress of Rheumatology, October 1973.

26. This study was supported in part by a grant from the Southern California Chapter of The Arthritis Foundation.

27. Requests for reprints should be addressed to: V. Hanson, M.D. Childrens Hospital of Los Angeles, P.O. Box 54700, Los Angeles, Calif. 90054 (USA)

28. Accepted for publication May 6, 1974.
5-Hydroxyindolylacetic acid norepinephrine phenylketonuria typhoid vaccine vanmandelic acid

\title{
Thermoregulation of Phenylketonuric Children
}

\author{
CLARK M. BLATTEIS, ${ }^{(36)}$ GERARD J. BILLMEIER, JR., AND THOMAS M. GILBERT \\ Department of Physiology and Biophysics and Child Development Center, The University of
} Tennessee Medical Units, Memphis, Tennessee, USA

\section{Extract}

Children with untreated phenylketonuria exhibited abnormalities in their thermoregulatory defenses against heat and cold. At $37^{\circ}$, they sweated minimally, but displayed normal cutaneous vasodilatation. At $8^{\circ}$, they shivered and vasoconstricted normally, yet failed to maintain core temperature. 3-Methoxy, 4-hydroxy-D-mandelic acid (vanmandelic acid, VMA) excretion (at $26^{\circ}$ ) was more depressed than that of 5-hydroxy-3-indolylacetic acid (5-HIAA) in these subjects. The apparent imbalance between these amines could account, according to the monoamine hypothesis of temperature regulation, for their deficient sweating in $37^{\circ}$, thereby implicating norepinephrine as a possible central transmitter in the sudomotor response of man to heat. On the other hand, the inadequate heat conservation observed at $8^{\circ}$ probably was caused by unfavorable physical characteristics, e.g., higher surface area to weight ratio, or smaller subcutaneous insulation.

\section{Speculation}

The present findings suggest a possible involvement of norepinephrine and serotonin in the hypothalamic control of body temperature in man, in that the balance between these 
monoamines may regulate sudomotor, but not vasomotor, responses to heat.

Feldberg and Myers (4) proposed that normal body temperature may be determined by the balanced rate of release of norepinephrine and serotonin locally in the anterior hypothalamus, and that temperature-regulating activity may be modulated by a reciprocal shift in this intrinsic balance. Thus, a change in temperature was visualized as the result of two simultaneous mechanisms: inhibition of the release of one and augmentation of the release of the other of these two putative neurotransmitter substances. Ample evidence exists that these factors, when injected intracerebrally in normal animals, may indeed play a role in the central control of body temperature $(7,21)$. Their precise function, however, remains uncertain. Moreover, because of the limitations in studying normal human subjects in comparable fashion, no data are available on the role of these transmitter substances in human thermoregulation. Consequently, the applicability of the monoaminergic model of temperature regulation to man is as yet only implied (18).

Subjects possessing, through inborn error, an imbalance of brain norepinephrine and serotonin might offer a useful human model for the investigation of this hypothesis. Such an imbalance exists in phenylketonuria, a genetic disorder of metabolism (9). In this condition, the high levels of phenylalanine and its derivatives inhibit, to unequal extents, the normal biosynthesis of sertonin and norepinephrine $(1,11$, $12,14,27)$. According to the monoamine hypothesis; untreated phenylketonurics should, therefore, manifest defective control of their body temperature. This study was undertaken to determine the thermoregulatory responses of untreated and treated children with phenylketonuria to varying thermal environments, and to a pyrogenic vaccine. The thermoregulation of phenylketonurics has not been investigated previously.

\section{MATERIAL AND METHODS}

Two untreated and four treated (23), postabsorptive, Caucasian, phenylketonuric children (PKUs), were studied (29). They shared the same inborn error of metabolism, but differed in that the treated group exhibited normal growth and development. Of the untreated subjects, subject 1 was nonambulatory and classified (6) profoundly, and subject 2 severely, mentally retarded; both exhibited significant growth and mass reductions (including subcutaneous fat). The physical characteristics of all of the subjects are presented in Table 1. All were trained in the procedures used in this study before its initiation.

The children, clad only in briefs, were individually exposed, at weekly intervals, to each of three environmental temperatures (dry bulb): (1) $26^{\circ}$ (relative humidity (RH) $43.8 \%$ ), (2) $37^{\circ}$ ( $\left.\mathrm{RH} 36.6 \%\right)$, and (3) $8^{\circ}(\mathrm{RH} 88.4 \%)$. Additionally, for purposes of replication, subject 1 was re-exposed to $37^{\circ}$, and subject 2 to $8^{\circ}$, 1 week after their initial exposure to these environments, respectively; and both were again exposed to $37^{\circ} 1$ year later. After appropriate measuring devices were implanted, they were allowed to stabilize in the respective test environments for $40 \mathrm{~min}$ before any measurements were begun, except for the $8^{\circ}$ exposure, which was acute. In this case, pretest stabilization occurred in $26^{\circ}$. Each test period lasted $1 \mathrm{hr}$, during which measurements were made over 5-min periods at 5-min intervals. These included: (1) pulmonary ventilation $\left(\dot{\mathrm{V}}_{\mathrm{E}}\right)$ and rate of oxygen consumption $\left(\dot{\mathrm{V}}_{\mathrm{O}_{2}}\right)$, determined by the open circuit method, utilizing a fitted face mask securely held by an attendant. The expired air volumes were measured using a precalibrated Parkinson-Cowan CD1 dry test spirometer, and the percentages of $\mathrm{O}_{2}$ in aliquots of the mixed expired air were determined by means of a Beckman B160 physiologic gas analyzer; the rate of $\mathrm{O}_{2}$ consumption was derived from these data. (2) Rectal $\left(\mathrm{T}_{\mathrm{re}}\right)$ and four skin (chest, upper arm, thigh, calf) temperatures were recorded with appropriate thermistor probes and a telethermometer (29); mean skin temperature $\left(\mathrm{T}_{\overline{\mathrm{sk}}}\right)$ was calculated according to the formula of Ramanathan (16). (3) Finger-pad blood flow $\left(\dot{\mathrm{m}}_{\mathrm{bl}} \mathrm{sk}\right)$ was measured by photoelectric plethysmography (30); the results were expressed as the amplitude of the cutaneous opacity pulses, in arbitrary units. (4) Shivering, as electromyographic activity, was recorded by surface electrodes over both brachioradialis and rectus femoris muscle groups; the potentials from these sites were added by means of a summing amplifier. The intensity of shivering was evaluated from these data as the amplitude-frequency product of the potential peaks (5). All of the above variables were recorded on a Beckman type RB Dynograph. (5) Heart rate was counted from the finger-pad pulse tracing. (6) Respiratory frequency was obtained by observation. (7) Distribution of sweating was measured by the iodine-starch paper method of Randall (17); total sweat loss was evaluated as the change in body mass during heat exposure.

An additional test condition involved the subcutaneous injection of a standardized dose $(0.25 \mathrm{ml})$ of typhoid vaccine, USP (31). The thermal response ( $\mathrm{T}_{\mathrm{re}}$ only) to this pyrogenic material was monitored in $26^{\circ}$ up to $48 \mathrm{hr}$ postinjection.

Table 1. Physical characteristics of subjects

\begin{tabular}{|c|c|c|c|c|c|c|c|}
\hline Subject & Sex & $\begin{array}{c}\text { Age at } \\
\text { diagnosis, } \\
\text { mo }\end{array}$ & $\begin{array}{l}\text { Age at } \\
\text { study, } \\
\mathrm{yr}^{1}\end{array}$ & $\begin{array}{l}\text { Body mass, } \\
\qquad \mathrm{kg}\end{array}$ & $\begin{array}{l}\text { Body } \\
\text { height, } \\
\mathrm{cm}\end{array}$ & $\begin{array}{c}\text { Surface } \\
\text { area, } \\
\mathrm{m}^{2}\end{array}$ & $\begin{array}{l}\text { Intellectual level } \\
(\text { AAMD })^{2}\end{array}$ \\
\hline \multicolumn{8}{|c|}{ Treated group } \\
\hline$A$ & $\mathrm{~F}$ & $11 / 2$ & $37 / 12$ & 18.3 & 97.8 & 0.75 & Superior \\
\hline$B$ & $\mathrm{~F}$ & 5 & $28 / 12$ & 12.6 & 90.2 & 0.58 & Borderline \\
\hline$C$ & M & $13 / 4$ & $38 / 12$ & 15.0 & 97.8 & 0.65 & Average \\
\hline$D$ & M & 2 & $19 / 12$ & 13.2 & 83.8 & 0.59 & Average \\
\hline \multicolumn{8}{|c|}{ Untreated group } \\
\hline 1 & M & 48 & $170 / 12$ & 22.5 & 127.0 & 0.88 & $\begin{array}{l}\text { Profound retardation; } \\
\text { nonambulatory }\end{array}$ \\
\hline 2 & $\mathrm{~F}$ & 58 & $177 / 12$ & 38.2 & 152.4 & 1.25 & $\begin{array}{l}\text { Severe retardation; } \\
\text { ambulatory }\end{array}$ \\
\hline
\end{tabular}

\footnotetext{
${ }^{1}$ These groups are not matched for age because the dietary treatment of phenylketonuria is a relatively recent innovation (26), so that few treated teen-aged phenylketonurics (PKUs) are currently available in the population. Conversely, since PKU infants now are not knowingly denied treatment, few untreated PKU infants exist in the population.

${ }^{2}$ American Association on Mental Deficiency (6).
} 
As an index of the extent of these subjects' biochemical lesion, the following compounds were measured before initiation of this study: serum phenylalanine, by the method of McCaman and Robins (10); 24-hr excretion of VMA in urine, according to the procedure of Pisano et al. (15); 5-HIAA, by the technique of Udenfriend et al. (24); and phenolic acids, by the method of Zelnicek and Slama (28).

For the statistical evaluations, the estimated regression line and $95 \%$ confidence interval for the results from the treated group were calculated, and significant differences between treated and untreated PKUs were identified when the data from the untreated PKUs fell outside these 95\% limits.

\section{RESULTS}

The serum phenylalanine levels in the treated subjects, although higher than normal, were within the therapeutic range (23); the high value for subject $C$ was spurious. The levels of serum phenylalanine and urinary phenolic acids were consistently higher in the untreated subjects, whereas the 24-hr excretion of VMA and 5-HIAA in urine was lower. Moreover, the mean excretion of VMA was proportionally more depressed $(90 \%)$ than that of 5 -HIAA $(72 \%)$ in this group.

\section{THERMOREGULATORY RESPONSES}

In $26^{\circ}$ Environment (Fig. 1). The values of the variables measured in the treated PKUs were within the normal range for their age group $(22,25)$ in this thermoneutral environment. Between the two untreated PKUs, only the finger-pad blood flow of subject $l$ was significantly smaller than that of the treated group. The oxygen consumption of both untreated subjects fluctuated around the lower limit of the normal range; their rectal and mean skin temperatures were not significantly different from those of the untreated PKUs.

In $37^{\circ}$ Environment (Fig. 2). Exposure to heat induced restlessness in all of the subjects and an elevation of their oxygen consumption, as compared with these responses in $26^{\circ}$. The rectal temperature of both untreated PKUs stabilized in the high normal range, whereas their mean skin temperature attained values significantly higher than those of the treated group; both exhibited intense cutaneous erythema. In marked contrast to the treated group, who sweated profusely over all the body, these subjects sweated minimally and in limited areas. Thus, sweat spots were detected principally (in decreasing order of counts) in subject 1 ; on the forehead, on the extensor surface of the forearms, and over the biceps; and

Table 2. Biochemical evaluation of metabolic lesion in all subjects at time of study

24-hr Excretion in urine

\begin{tabular}{lcccc}
\cline { 2 - 5 } Subject & $\begin{array}{c}\text { Serum } \\
\text { phenyl- } \\
\text { alanine, } \\
\mathrm{mg} / 100 \mathrm{ml}\end{array}$ & $\begin{array}{c}\text { Phenolic } \\
\text { acids, } \\
\mathrm{mg} / 100 \mathrm{ml}\end{array}$ & $\begin{array}{c}\text { VMA, } \\
\mathrm{mg} / \mathrm{liter}\end{array}$ & $\begin{array}{c}\text { 5-HIAA, } \\
\mathrm{mg} / \mathrm{liter}\end{array}$ \\
\hline Treated group & & & & \\
$A$ & 8.2 & 0 & 5.28 & 4.13 \\
$B$ & 3.8 & 0 & 4.90 & 1.31 \\
$C$ & 15.3 & 0 & 5.00 & 3.24 \\
$D$ & 5.7 & 0 & 2.55 & 5.29 \\
Untreated group & 18.0 & 100 & 0.35 & 1.18 \\
1 & 16.0 & 70 & 0.56 & 0.81 \\
2 & & & & \\
\hline
\end{tabular}

${ }^{1}$ VMA: vanmandelic acid; 5-HIAA: 5-hydroxy-3-indolylacetic acid.
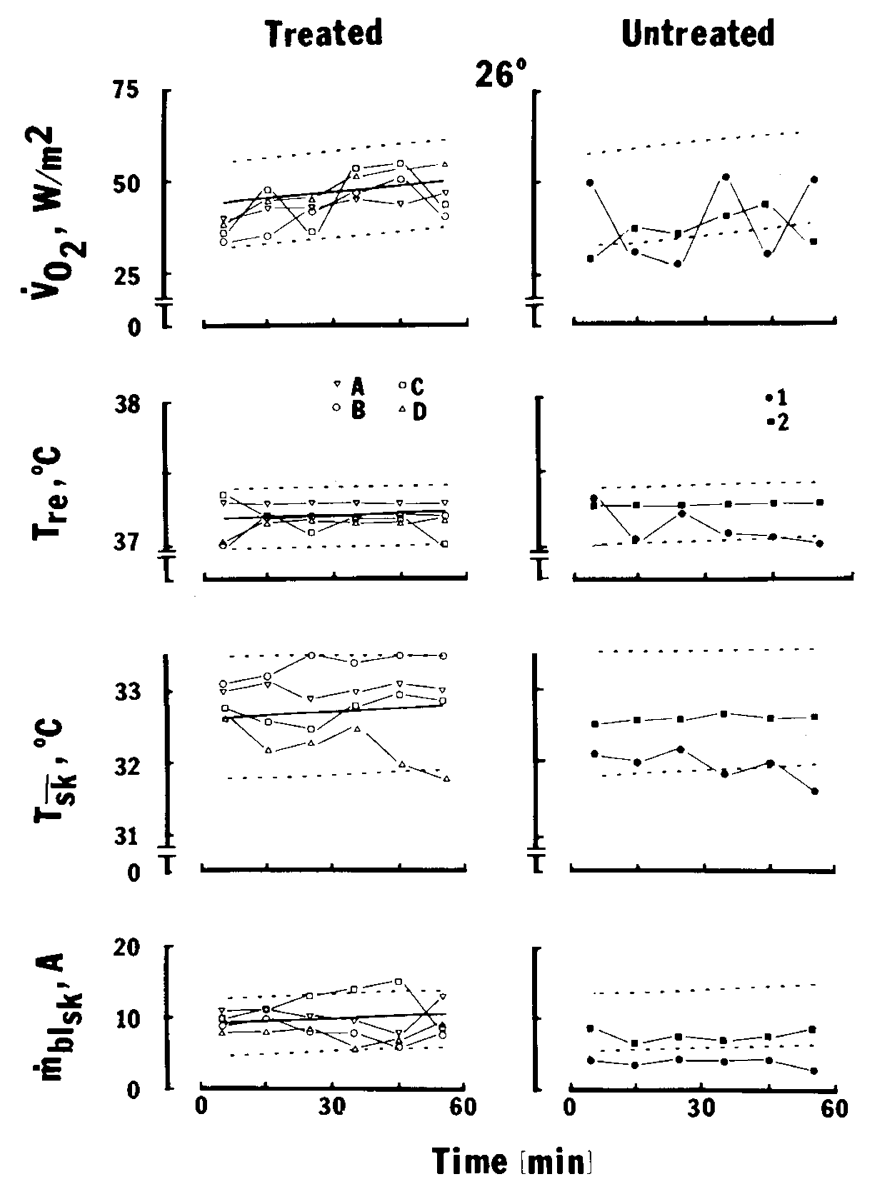

Fig. 1. Rate of oxygen consumption $\left(\mathrm{V}_{\mathrm{O}_{2}}\right)$, rectal $\left(\mathrm{T}_{\text {re }}\right)$ and mean skin $\left(\mathrm{T}_{\mathrm{sk}}\right)$ temperatures, and finger-pad blood flow $\left(\dot{\mathrm{m}}_{\mathrm{bl}_{\mathrm{sk}}}\right)$ of four treated (left) and two untreated (right) phenylketonuric children exposed to $26^{\circ}$. - : mean response for each variable in the treated subjects; - - - $95 \%$ confidence interval of this regression line.

in subject 2: on the upper mammary region of the chest, on the forehead, and infraorbitally. In addition, the onset of sweating appeared to be delayed in the untreated as compared with the treated PKUs. The total reduction in body mass of each of these untreated subjects equaled $0.5 \%$ of their preheat exposure weight, as compared with $1.4 \pm 0.1 \%$ for the treated group. The finger-pad blood flow of all the subjects was significantly higher in this warm environment than in $26^{\circ}$. However, the measured blood flow of subject $l$ was significantly smaller than that of the others, although the relative magnitude of his increase $(13.5 \%)$ was not significantly different from that of the rest $(15.4 \pm 11.4 \%)$. The responses of the untreated subjects did not vary during any of the replicate exposures.

In $8^{\circ}$ Environment (Fig. 3). None of the treated PKUs subjectively tolerated this exposure longer than $45 \mathrm{~min}$. All of the subjects shivered vigorously. However, shivering movements became manifest sooner in the treated than in the untreated PKUs after their entry into the cold environment $(6.2 \pm 2.5$ min for the treated, and 11.1 and $10.5 \mathrm{~min}$ for untreated PKUs, subjects 1 and 2 , respectively); they attained maximum intensity virtually from their respective onset, and were not significantly different thereafter. The oxygen consumption of all of the subjects was increased significantly and to a proportionate degree above the values in $26^{\circ}$. However, the values of both untreated PKUs differed significantly from those of the treated PKUs, i.e., that of subject 1 was greater, whereas that of subject 2 was smaller, probably because of behavioral differences between the two subjects. Thus, subject 


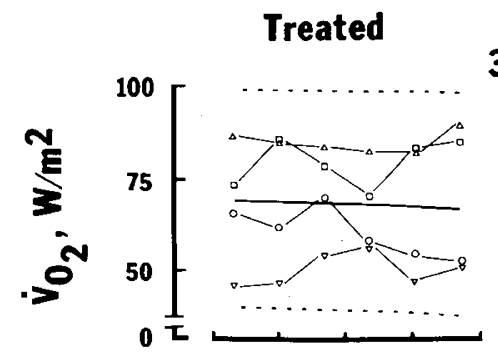

$37^{\circ}$

Untreated
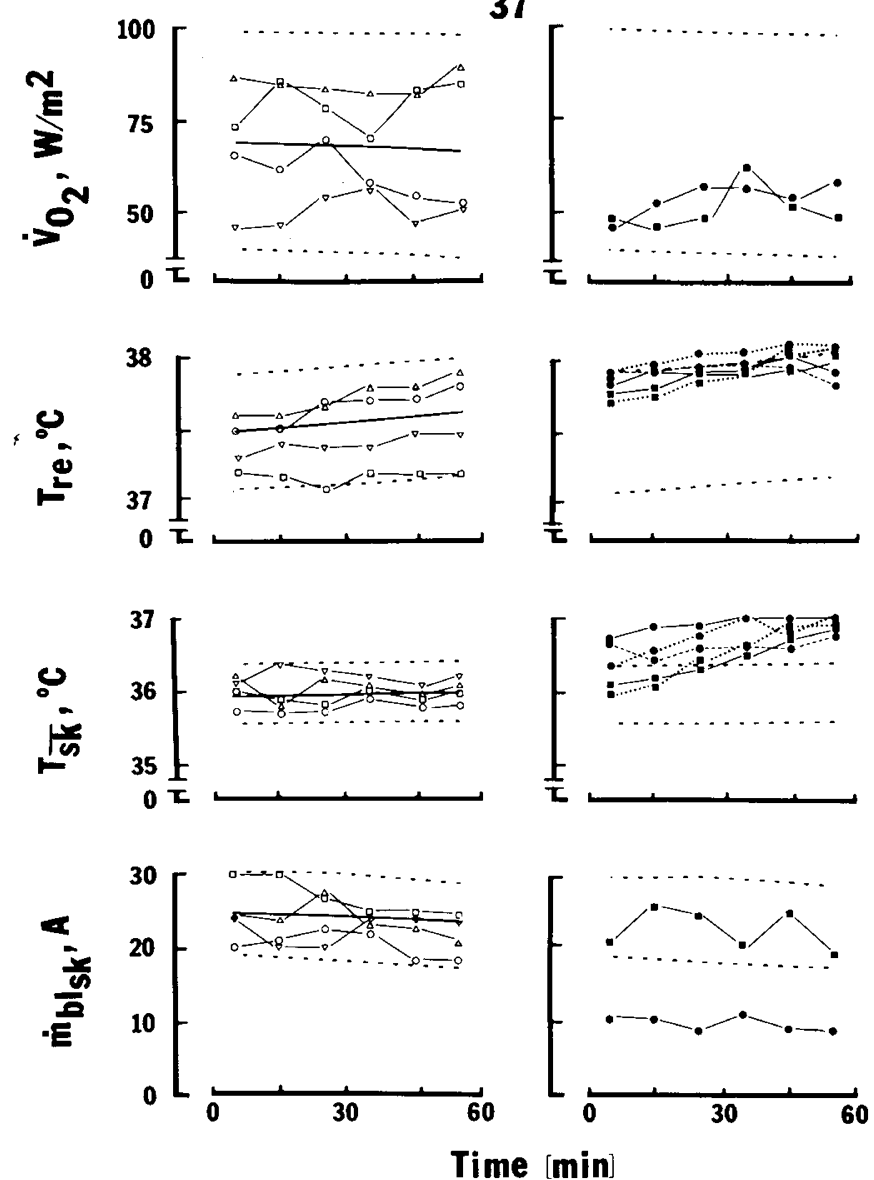

Fig. 2. The response of the variables shown during exposure of phenylketonuric children to $37^{\circ}$. Symbols and representations as in Figure 1. $\bullet-\bullet$ : first re-exposure; $\bullet \cdots \bullet, \bullet \cdots \bullet$ : second re-exposure (see text).

1 was hyperkinetic, spontaneously alternating during this exposure between a curled-up position and a rocking to-and-fro motion; subject 2 , on the contrary, was very apprehensive, as manifested by breath holding and generalized tensing. The rectal temperature of untreated subject 1 was not maintained, falling outside the limits of the tieated group 25 min after the onset of cold exposure. The degree of fall in mean skin temperature of all of the subjects was similar. Finger-pad blood flow was significantly diminished during cold exposure in both treated and untreated PKUs. However, the observed blood flow of subject 1 was significantly smaller than all the others, but its proportionately greater reduction from control $(82.9 \%)$ was still within the $95 \%$ confidence range for the other subjects $(61.3 \pm 21.0 \%)$. The responses of subject 2 to both her cold exposures were similar.

\section{TYPHOID VACCINE}

Three of the four treated PKUs developed fever within $4 \mathrm{hr}$ after the administration of the vaccine. On the other hand, neither untreated PKU fevered in response to this endotoxic challenge up to 48-hr postinjection. However, this difference in febrile responsiveness between the two groups was not statistically significant (by chi square test).

\section{CARDIOPULMONARY RESPONSES (TABLE 3)}

In $26^{\circ}$ Environment. The heart rate of all the subjects was in the high normal range for their respective age (26), although the rate for subject $l$ was lower than the rest. The pulmonary

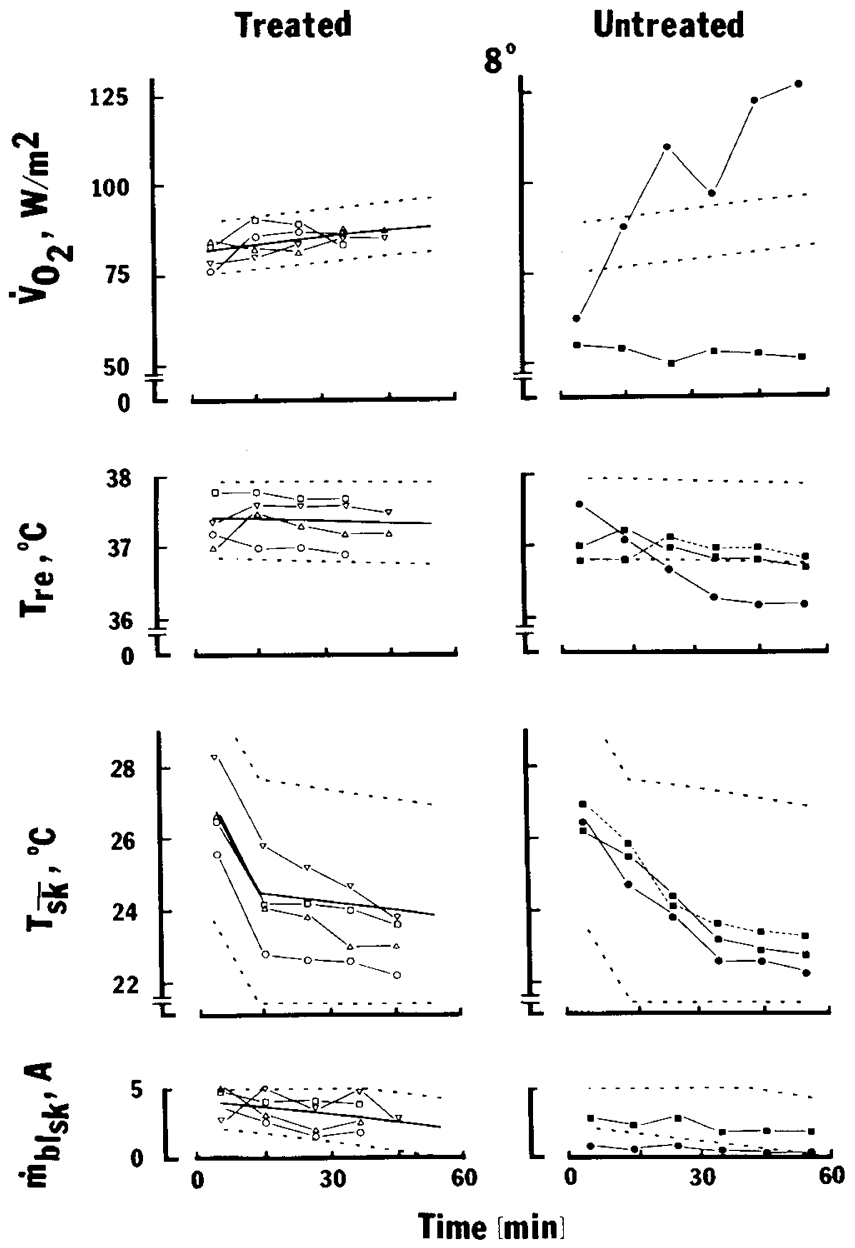

Fig. 3. The effect of exposure to $8^{\circ}$ on the variables shown in phenylketonuric children. Symbols and representations as in Fig. 1. -. - - : first re-exposure (see text).

ventilation $\left(\dot{\mathrm{V}}_{\mathrm{E}}\right)$ of the untreated PKUs was significantly lower than that of the treated subjects in this environment, whereas respiratory frequency (f) was comparable in both groups. The time course of these ventilatory and cardiac responses paralleled the rate of oxygen consumption.

In $37^{\circ}$ Environment. Exposure to heat induced a small, yet significant, increase in heart rate in both the treated and untreated PKUs, with a relatively greater increase observed in subject $l(18.4 \%)$ than in all the rest. Pulmonary ventilation also was increased in both groups $(9.2 \pm 6.0 \%$ for the treated PKUs); however, the untreated PKUs, espetially subject 1 , exhibited a proportionately larger increase (14.0 and $13.5 \%$ for subjects 1 and 2 , respectively). A moderate tachypnea also occurred in all of the subjects.

In $8^{\circ}$ Environment. All of the subjects, except untreated PKU, subject 2, showed an increase in heart rate and pulmonary ventilation in this environment. Indeed, subject $I$ exhibited the greatest degree of tachycardia and hyperventilation among all of the subjects in response to this cold stress. In opposition to the others, however, he decreased his respiratory rate. The overall time course of the cardiac and ventilatory responses of both the treated and untreated PKUs again paralleled their rate of oxygen consumption in this environment.

\section{DISCUSSION}

The present results indicate that the temperature regulation of untreated PKUs may be inadequate outside the thermoneutral $\left(26^{\circ}\right)$ zone. Thus, at $37^{\circ}$, the sweating response of 
Table 3. Cardiac and ventilatory responses of all subjects to each test environment ${ }^{1}$

\begin{tabular}{|c|c|c|c|}
\hline & $26^{\circ}$ & $37^{\circ}$ & $8^{\circ}$ \\
\hline \multicolumn{4}{|l|}{ HR, beats/min } \\
\hline Treated PKUs ${ }^{2}$ & $105 \pm 2$ & $115 \pm 2$ & $115 \pm 4$ \\
\hline Untreated PKU, subject $1^{3}$ & $88 \pm 2$ & $105 \pm 2$ & $120 \pm 11$ \\
\hline Untreated PKU, subject $2^{3}$ & $101 \pm 3$ & $112 \pm 3$ & $101 \pm 7$ \\
\hline \multicolumn{4}{|l|}{$\dot{\mathrm{V}}_{\mathrm{E}}, \mathrm{ml} / \mathrm{kg} / \mathrm{min}$ BTPS } \\
\hline Treated PKUs² & $316 \pm 16$ & $345 \pm 25$ & $495 \pm 19$ \\
\hline Untreated PKU, subject $1^{3}$ & $162 \pm 5$ & $225 \pm 11$ & $383 \pm 31$ \\
\hline Untreated PKU, subject $2^{3}$ & $144 \pm 7$ & $161 \pm 9$ & $158 \pm 9$ \\
\hline \multicolumn{4}{|l|}{ f, breaths/min } \\
\hline Treated PKUs ${ }^{2}$ & $23 \pm 1$ & $26 \pm 1$ & $28 \pm 1$ \\
\hline Untreated PKU, subject $1^{3}$ & $20 \pm 1$ & $22 \pm 1$ & $16 \pm 1$ \\
\hline Untreated PKU, subject $2^{3}$ & $20 \pm 1$ & $21 \pm 1$ & $21 \pm 1$ \\
\hline
\end{tabular}

${ }^{1} \mathrm{HR}$ : heart rate; PKUs: phenylketonurics; BTPS: body temperature, ambient pressure, saturated with water vapor.

${ }^{2}$ Values are means \pm 1 SEM for four subjects, recorded over $60 \mathrm{~min}$ at 10 -min intervals.

${ }^{3}$ Values indicate each subjects' response $\pm \mathrm{SD}$, recorded over $60 \mathrm{~min}$ at $10-\mathrm{min}$ intervals.

both untreated children was significantly reduced, as compared with that of the treated group; and at $8^{\circ}$, profoundly retarded subject 1 could not maintain his core temperature. Comparison of the responses of subjects 1 and 2 suggests, moreover, that the degree of impairment of temperature regulation may be proportionate to the severity of the functional retardation consequent to this disease.

Several explanations are possible for the impaired sweating function of both these untreated PKUs in the warm environment, as follows. (1) Immaturity of the end organs could be responsible for the impairment. However, since a moderate number of sweat glands was activated during heat exposure, and since sweating reactions to sudorific drugs have been demonstrated in other, untreated PKUs (8), it would appear unlikely that the defect can be attributed to this cause. (2) Incompetence of autonomic pathways is another possibility. The occurrence in both untreated PKUs of appropriate thermoeffector responses at $37^{\circ}$ (i.e., cutaneous vasodilatation and sweating) would seem to rule out impairment of afferent pathways. However, the minimal sweating in conjunction with the apparently normal vasomotor reaction during this exposure might indicate partial impairment of integrative and/or efferent neural mechanisms; however, a defect in the latter would seem improbable because of the absence of clinical signs of decreased sympathetic tone in the present untreated PKUs. (3) Incomplete central myelination (3) could account for dysfunction of those neuronal pathways in the hypothalamus involved in the stimulation and/or integration of sweating, in particular, which implies that the mechanisms for heat-induced vasodilatation and sweating might be under separate hypothalamic controls, a possibility compatible with previous suggestions (19). Finally, (4) hypothalamic monoamines imbalance should be considered. In agreement with previous reports $(1,11,12,14,27)$, the normal ratio between central norepinephrine and serotonin may have been unbalanced in the present untreated PKUs, as judged from the greater depression of the excreted level of VMA than that of 5-HIAA. Although we recognize that the products of these amines in urine were not measured during exposure to the test environment and, in addition, that extrapolation from urinary excretory to central levels is hazardous, it might, nevertheless, be speculated that this inherent imbalance accounts for the observed defect in sweating. Thus, in accordance with the monoamine hypothesis of thermoregulation $(4,7,21)$, the present results may be interpreted as suggesting that norepinephrine might operate in man as a central transmitter in the sudomotor response to heat. Such a role for norepinephrine would be consistent with its implied function in subhuman primates (13), and also with the concept of a dual control of vasomotor and sudomotor responses to heat (19).

If indeed norepinephrine mediates the responses against overheating, it also might be speculated, in conformity with the monoaminergic model of thermoregulation, that serotonin would be involved in the defenses against overcooling. The relatively elevated level of serotonin and the apparently unimpaired thermoregulatory response to cold (i.e., vigorous shivering and cutaneous vasoconstriction) of the untreated PKUs would be consistent with this hypothesis. Therefore, the inability of subject 1 to maintain his core temperature in the $8^{\circ}$ environment probably represents a defect in heat conservation in this subject, attributable to his structural underdevelopment, his consequently higher surface area to weight ratio, and his smaller subcutaneous insulation, physical factors that are known to influence the stability of body temperature $(2,20)$.

The failure of the untreated PKUs to develop fever after typhoid vaccine is at variance with the result that would be predicted by the monoamine hypothesis, in that if the monoamines were involved, a protracted febrile reaction should have occurred. To the contrary, if monoamine release were not involved in the febrile response, a normal pyrogenic response should have been observed. The lack of any response in these children may, therefore, have been an artifact of the small sample size, and/or be related to other dysfunctions of this disease (e.g., incomplete central myelination, impaired hypothalamic integration). In any case, the published evidence (21) for a role of the monoamines in pyrogenic responsiveness is conflicting.

Although the etiology of the observed thermoregulatory derangements remains unclarified, these results nevertheless have implications for the clinical management of untreated PKUs. Thus, unnecessary exposure of such patients to temperature extremes (especially heat) should be avoided, and periodic monitoring of body temperature during changes in ambient temperature is encouraged. Indeed, nursing observations of untreated subject 1 report cutaneous ery thema and suspected heat intolerance during a very hot day. The present findings, therefore, reaffirm the value of early diagnosis and dietotherapy in phenylketonuria $(9,23)$, as evidenced by the normal temperature-regulating ability $(22,25)$ of the present treated, as compared with the untreated, subjects. This conclusion is further supported by the lack of history of heat or cold intolerance in these treated PKUs.

\section{SUMMARY}

The thermoregulatory responses of treated and untreated phenylketonuric children to heat $\left(37^{\circ}\right)$ and to cold $\left(8^{\circ}\right)$ were compared. The treated subjects thermoregulated normally during both the warm and cold exposures. In contrast, the untreated PKUs sweated minimally, but displayed normal cutaneous vasodilatation in the warm environment. In the cold, they shivered and vasoconstricted normally. The different responses between the two groups might be attributable to an imbalance between hypothalamic monoamines present in the untreated subjects. This study suggests that norepinephrine might be a central transmitter in the sudomotor response of man to heat.

\section{REFERENCES AND NOTES}

1. Boylen, J. B., and Quastel, J. H.: Effects of L-phenylalanine and sodium phenylpyruvate on the formation of adrenaline from L-tyrosine in adrenal medulla in vitro. Biochem. J., 80: 644 (1961).

2. Buskirk, E. R, and Kollias, J.- Total body metabolism in the cold Bull. N. Y. Acad. Sci., (special symposium issue): 17 (1969).

3. Crowe, L., and Pare, C. M. B.: Phenylketonuria: A review and a report of the pathological findings in four cases. J. Ment. Sci., 106: $862(1960)$ 
4. Feldberg, W., and Myers, R. D.: Effects on temperature of amines injected into the cerebral ventricles: A new concept of temperature regulation. J. Physiol. (London), 173: 226 (1964).

5. Goepfert, E., von Eiff, A. W., and Howind, C.: Quantitative Bezichungen zwischen Energiestoffwechsel und reflektorischen Musskeltonus bei der Thermoregulation Z. Ges. expl. Med., 120: 308 (1953).

6. Heber, R.: A manual on terminology and classification in mental retardation. Amer. J. Ment. Defic. Suppl., 64 (1959).

7. Hellon, R. Central transmitters and thermoregulation. In: J. Bligh and $\mathrm{R}, \mathrm{E}$. Moore: Essays on Temperature Regulation, pp. 71-85 (American Elsevier, New York, 1972).

8. Jounela, A. J., and Kivimäki, T.: Possible sensitivity to meperidine in phenylketonuria. N. Engl. J. Med., 228: 1411 (1973).

9. Knox, W. E.: Phenylketonuria. In: J. B. Stanbury, J. B. Wyngaarden, and D. B. Frederickson: Metabolic Basis of Inherited Disease, pp. 266-295, (McGraw-Hill, New York, 1972).

10. McCaman, M. W., and Robins, E.: Fluorometric method for determination of phenylalanine in serum. J. Lab. Clin. Med., 59: 855 (1962).

11. McKean, C. M.: The effects of high phenylalanine concentrations on serotonin and catecholamine metabolism in the human brain. Brain Res., 47: 469 (1972).

12. Menkes, J. H.: The pathogenesis of mental retardation in phenylketonuria and other inborn errors of amino acid metabolism. Pediatrics, 39: 297 (1967).

13. Myers, R. D.: Primates. In: G. C. Whittow: Comparative Physiology of Thermoregulation. Vol. II: Mammals, pp. 283326 (Academic Press, New York, 1971).

14. Pare, C. M., Sandler, M., and Stacey, R. S.: 5-Hydroxytryptamine deficiency in phenylketonuria. Lancet, $i: 551$ (1957).

15. Pisano, J., Crout, J. R., and Abraham, D.: Determination of 3-methoxy-4-hydroxymandelic acid in urine. Clin. Chim. Acta, 7: 285 (1962).

16. Ramanathan, N. L.: A new weighting system for mean surface temperature of the human body. J. Appl. Physiol., 19: 531 (1964).

17. Randall, W. C.: Quantitation and regional distribution of sweat glands in man. J. Clin. Invest., 25: 761 (1946).

18. Rawlins, M. D., and Granston, W. I.: Clinical studies on the pathogenesis of fever. In: E. Schönbaum, and P. Lomax: The Pharmacology of Thermoregulation (Symposium), pp. 264-277 (Karger, Basel, 1973).

19. Senay, L. C., Jr.: Cutaneous vascular responses of dehydrated men following ingestion of saline or water. Proc. Soc. Exp. Med. Biol., 141: 232 (1972).

20. Shvartz, E., Saar, E., and Benor, D.: Physique and heat tolerance in hot-dry and hot-humid environments. J. Appl. Physiol., 34: 799

Copyright $\odot 1974$ International Pediatric Research Foundation, Inc.
(1973).

21. Snell, E. S.: Endotoxin and the pathogenesis of fever. In: S Kadis, G. Weinbaum, and S. J. Ajl: Microbial Toxins, pp. 277-340 (Academic Press, New York, 1971).

22. Talbot, F. B.: Skin temperatures of children. Amer. J. Dis. Child., 42: 965 (1931).

23. Treatment of phenylketonuria: report to the medical research council of the conference on phenylketonuria. Brit. Med. J., 1: 1691 (1963).

24. Udenfriend, S., Titus, E., and Weissbach, H.: The identification of 5-hydroxy-3-indoleacetic acid in normal urine and a method for its assay. J. Biol. Chem., 216:499 (1955).

25. Van der Bogert, F., and Moravec, C. L.: Body temperature variations in apparently healthy children. J. Pediat., 10: 466 (1937).

26. Vaughan, V. C., III: Growth and development. In: W. E. Nelson Textbook of Pediatrics, p. 40 (Saunders, Philadelphia, 1964).

27. Yuwiler, A., Geller, F., and Slater, G. C.: On the mechanism of the brain serotonin depletion in experimental phenylketonuria. J. Biol. Chem., 240: 1170 (1965).

28. Zelnicek, E., and Slama, J.: Phenylpyruvate and $O$-hydroxy phenylacetate in phenylketonuric urine. Clin. Chim. Acta, 35: 496 (1971).

29. Yellow Springs Instrument Co., Inc., Yellow Springs, Ohio.

30. Photoelectric pulse transducer type 323, Narco Bio-Systems, Inc., Houston, Tex.

31. Eli Lilly \& Co., Indianapolis, Ind.

32. Informed consent, authorized by parents or legal guardians, was obtained by the investigators to study each subject. Requirements for human research were met as promulgated by the Patient Participation Committee, University of Tennessee Medical Units, and the Human Rights and Research Committee, Arlington Hospital and School.

33. The authors gratefully acknowledge the skilled technical assistance of Ms. Rose-Linda Baldwin. They also thank the staff of the Arlington Hospital and School. They further are indebted to Drs. Charles Smith and Tom Brooks for the biochemical determinations.

34. The preliminary results of this study were presented at the 57 th Annual Meeting of the Federation of American Societies for Experimental Biology in Atlantic City, N. J., April 1973.

35. This work was supported by United States Public Health Service Grants nos. AI 09957 and HSMHA 900.

36. Requests for reprints should be addressed to: C. M. Blatteis, M.D. Department of Physiology and Biophysics, The University of Tennessee Medical Units, 894 Union, Box NA 427, Memphis, Tenn. 38163 (USA)

37. Accepted for publication May 14, 1974

Printed in U.S.A. 